OPEN ACCESS

Edited by:

Hongfang Jin,

Peking University First Hospital, China

Reviewed by:

Shiwei Yang,

Children's Hospital of Nanjing Medical

University, China

Li Zi Pu,

Qingdao Women \& Infants

Hospital, China

*Correspondence:

Jiawei Shi

shijiawei@21cn.com

Hua Peng

phua20120101@163.com

Specialty section:

This article was submitted to

Pediatric Cardiology,

a section of the journal

Frontiers in Pediatrics

Received: 01 July 2019 Accepted: 09 September 2019

Published: 01 October 2019

Citation:

Guo Q, Liu J, Zhu P, Liu Y, Dong N, Shi $J$ and Peng $H$ (2019) Evaluation of Drug-Related Receptors in Children With Dilated Cardiomyopathy. Front. Pediatr. 7:387.

doi: 10.3389/fped.2019.00387

\section{Evaluation of Drug-Related Receptors in Children With Dilated Cardiomyopathy}

\author{
Qing Guo ${ }^{1}$, Jie Liu ${ }^{1}$, Peng Zhu ${ }^{2}$, Yali Liu ${ }^{1}$, Nianguo Dong ${ }^{2}$, Jiawei Shi ${ }^{2 *}$ and Hua Peng ${ }^{1 *}$ \\ ${ }^{1}$ Department of Pediatrics, Union Hospital, Tongji Medical College, Huazhong University of Science and Technology, Wuhan, \\ China, ${ }^{2}$ Department of Cardiovascular Surgery, Union Hospital, Tongji Medical College, Huazhong University of Science \\ and Technology, Wuhan, China
}

Background: Effective treatments for pediatric dilated cardiomyopathy (DCM) are limited. Currently, pediatric DCM therapy mainly includes supportive heart failure (HF) treatment. While the treatment for child DCM patients is generally the same as that for adult DCM patients, few randomized prospective studies on the clinical efficacy of treatments for pediatric DCM have been published. We explored the appropriate treatments for child patients.

Methods: The ultrastructure of pediatric DCM and control hearts was analyzed by electron microscopy and HE staining. Left ventricular tissues from children in the DCM and control groups were subjected to quantitative RT-PCR (qRT-PCR) to study the mRNA expression of receptors related to various treatments, including drugs targeting the renin-angiotensin-aldosterone system (RAAS) system, digoxin, milrinone, and $\beta$-receptor blockers, in child patients in the clinic. Furthermore, the differences in drug receptors in heart tissues between children and adults with DCM were analyzed.

Results: Compared with the control children, the children in the DCM group showed marked abnormalities in structure and organelles. The mRNA levels of angiotensin-converting enzyme (ACE), REN, prorenin receptor (PRR), NEP, ATP1A1, and phosphodiesterase3 (PDE3A) were higher in the pediatric DCM group than the control group. Interestingly, the mRNA expression of these treatment-related receptors was much higher in children than in adults.

Conclusion: ACE inhibitors, PRR or REN receptor inhibitors, PDE3 inhibitors and LCZ696 may be effective in children with DCM. However, $\beta$-receptor blockers are not valid treatments for pediatric DCM. Moreover, high receptor expression was observed in children. These data will improve the selection of drugs for DCM patients, enhance treatment, and increase the survival rate.

\footnotetext{
Keywords: children, dilated cardiomyopathy, receptors, treatment, RAAS
} 


\section{INTRODUCTION}

Dilated cardiomyopathy (DCM) is a kind of cardiomyopathy that involves left ventricular (LV) dilation and systolic dysfunction without abnormal load conditions and severe coronary artery disease (1). The annual incidence of pediatric DCM is 0.58 cases per 100,000 person-years (2). Effective treatments for pediatric DCM are limited. Currently, therapy for DCM in children mainly includes supportive heart failure (HF) treatment. According to the current guidelines, pharmacotherapy involving $ß$-blockers and angiotensin-converting enzyme (ACE) inhibitors is the basis of pediatric HF therapy; however, viable randomized prospective studies are lacking (3). In addition, treatments such as furosemide, milrinone, and digoxin, which are commonly used to treat adult HF, are used to treat child HF. Although, the current treatment of adult HF has shown some success with these drugs, these same therapies do not seem to be effective for pediatric HF. Specifically, treatment of adult HF with PDE3A inhibitors led to an increased incidence of sudden death and arrhythmias (4). Treatment with PDE3A inhibitors improved symptoms in pediatric $\mathrm{HF}$ patients without increasing the incidence of arrhythmias or sudden death (5).

Activation of $\beta$-adrenergic and renin-angiotensin-aldosterone system (RAAS) receptors plays an important role in the treatment of adult HF and cardiac remodeling (6). RAAS is important regulator of blood pressure, and suppression of RAAS can decrease cardiac load and relieve HF. RAAS include some classic receptors such as NR3C2, prorenin receptor (PRR), ACE, REN. The $\beta$-adrenergic receptors of the myocardium play an important role in the regulation of heart function. Many studies reported that an over-expression of the ADRB1 ( $\beta 1$-adrenoceptor) are which is one of the main $\beta$-adrenergic receptors may contribute to heart failure. Treatment of HF and atrial fibrillation with cardiac glycosides can inhibit the $\mathrm{Na}+, \mathrm{K}+$-ATPase. A large catalytic subunit (alpha) and a small glycoprotein subunit (beta) compose $\mathrm{Na}+, \mathrm{K}+-\mathrm{ATPase}$. The ATP1A1 gene encodes an alpha 1 subunit with good affinity for digoxin (7). These genes are involved in HF and LV remodeling (8). A member of the cGMPinhibited cyclic nucleotide phosphodiesterase family is encoded by the PDE3A gene. Thus, inhibition of the protein encoded by the PDE3A gene may be an effective treatment for congestive HF (9). Neprilysin encoded by the NEP gene is a neutral endopeptidase that is a potential target for the treatment of HF and hypertension due to its functions in vasodilation, natriuresis, and fibrosis (10).

We suggest that the mechanisms of HF may be different in children and adults and that different cellular mechanisms may be involved in pediatric HF. We evaluated the effect of drugs on the treatment of children with DCM by measuring mRNA expression of the corresponding drug-related receptors in cardiomyocytes after HF treatment in this study.

\section{MATERIALS AND METHODS}

\section{Human Samples}

Child DCM samples ( $n=11$; age $<16$ years) were obtained from Wuhan Union Hospital from January 2017 to October
2018 during heart transplantation due to end-stage idiopathic DCM. All cases of children DCM who underwent heart transplantation in this study were confirmed as primary DCM through discussion and approval by members of the heart transplantation committee. In addition, this research ethics has been approved by the medical ethics committee of Tongji medical college, Huazhong University of Science and Technology and all the patients' family members had signed informed consent before taking samples of this study. The clinical history and blood tests of these pediatric patients were available (Table 1). Adult DCM samples ( $n=10$; age $20-60$ years) were obtained from Wuhan Union Hospital from January 2016 to 2018 from patients who underwent transplantation due to end-stage DCM and had no cardiac complications, such as hypertension, coronary atherosclerosis, and myocarditis. Control samples $(n=7)$ were from donor hearts that could not be transplanted for technical reasons (blood type or size mismatch) with normal LV function and active infection or no history of myocardial disease. The LV tissue underwent rapid dissection, rapid freezing, and preservation at $-80^{\circ} \mathrm{C}$ when cardiac explants were taken from the operating room. Another LV sample was fixed in either $10 \%$ formalin or $2.5 \%$ glutaraldehyde.

\section{Electron Microscopy}

Cardiac specimens $\left(2 \mathrm{~mm}^{2}\right)$ were fixed with $0.15 \mathrm{M}$ cacodylate buffer at pH 7.4 containing $2 \mathrm{mM}$ calcium chloride at $4^{\circ} \mathrm{C}$ overnight. Then, $0.15 \mathrm{M}$ cacodylate buffer was used to rinse the specimens 3 times for $10 \mathrm{~min}$ each. Next, the specimens were fixed in $1 \%$ osmium tetroxide containing $1.5 \%$ potassium ferrocyanide in cacodylate buffer for $1 \mathrm{~h}$. We used ultrapure water the wash samples 3 times and stained them en bloc for $1 \mathrm{~h}$. Then, the samples were again washed with ultrapure water. Specimens were dehydrated in a graded acetone series (50, 70, 90, 100\%) for $10 \mathrm{~min}$ twice. The specimens were fixed and incubated at $60^{\circ} \mathrm{C}$ for $48 \mathrm{~h}$. We used a diamond trim tool (Daitome Ultra $45^{\circ}$ ) to trim each block. The slices were placed into $2 \%$ uranium acetate saturated alcohol solution and then lead citrate (15 min each staining) and were dried at room temperature overnight. An electron microscope (HITACHI HT7700) was used to observe and collect images.

\section{qRT-PCR Assay}

Total RNA was extracted from LV cardiac tissue by using TRIzol reagent according to the manufacturer's instructions (Sigma, St. Louis, MO), and reverse transcription reactions were performed using an All-in-One synthesis kit (GeneCopoeia, USA) according to the manufacturer's recommendations. RT-PCR was performed using a Bio-Rad CFX manager. A total reaction volume of 10 $\mu \mathrm{l}$ contained $1 \mu \mathrm{l}$ of cDNA, $5 \mu \mathrm{l}$ of All-in-One RT-PCR mix solution (GeneCopoeia, USA), $1 \mu \mathrm{l}$ each of sense and antisense primers $(10 \mu \mathrm{M})$, and up to $2 \mu \mathrm{l}$ of $\mathrm{ddH}_{2} \mathrm{O}$. Primer sequences are listed (Supplement 1). The PCR amplification conditions were $95^{\circ} \mathrm{C}$ for $10 \mathrm{~min}$ and 39 cycles of $95^{\circ} \mathrm{C}$ for $10 \mathrm{~s}, 55^{\circ} \mathrm{C}$ for $30 \mathrm{~s}$, and $72^{\circ} \mathrm{C}$ for $30 \mathrm{~s}$, followed by $65^{\circ} \mathrm{C}$ for $5 \mathrm{~s}$ and $95^{\circ} \mathrm{C}$ for $5 \mathrm{~s}$. GAPDH mRNA levels were used for normalization, and the relative mRNA expression was calculated by the $2^{-\Delta \Delta C t}$ method. 


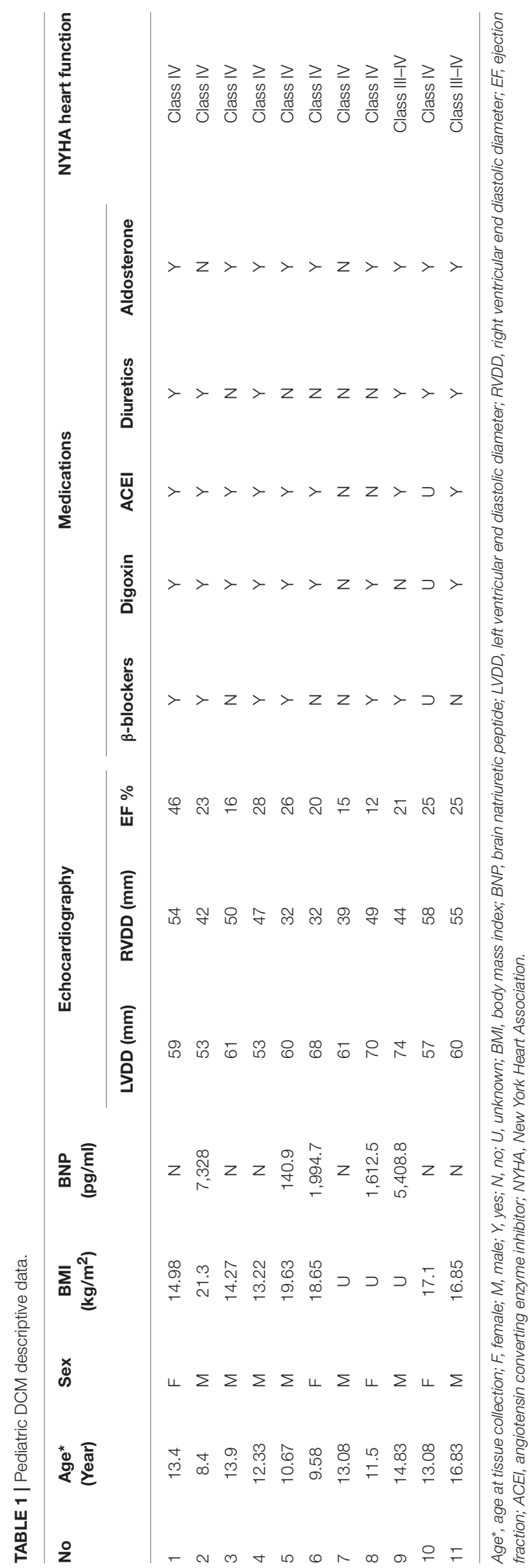

\section{Data Analysis}

All statistical analyses of qRT-PCR data were performed with GraphPad Prism software (GraphPad Software, Inc.). Variables were compared between the groups using comparison of two groups after analysis of variance (ANOVA). Statistical significance was set a priori at $p<0.05$, and all data are presented as the mean \pm SEM in the figures.

\section{RESULTS}

Children with DCM in this group who underwent heart transplantation had an age range of 8-17 years old, with an average age of $12.5 \pm 2.4$ years, and the ratio of males to females was 7:4. The LV ejection fraction (LVEF) ranged from $12 \%$ to $46 \%$, with an average of $23 \pm 9 \%$. The average LV end diastolic diameter (LVDD) was $61.45 \pm 6.684 \mathrm{~mm}$, and the average right ventricular end diastolic diameter (RVDD) was $45.64 \pm 8.8 \mathrm{~mm}$. The mean BNP level in this group was 3,297 $\pm 2,967 \mathrm{pg} / \mathrm{ml}$, while the normal value of BNP in our hospital was $<100 \mathrm{pg} / \mathrm{ml}$; the BNP value in the DCM group was at least 14 times higher than the normal value. All patients had a New York heart function of IV (Table 1).

\section{Pathology and Ultrastructure in Pediatric DCM}

We observed the pathology of HE-stained myocardial tissues by light microscopy. LV myocardial fibers in the DCM group showed a variable thickness with blurred transverse striae. Some myocardial fibers were thick, the nuclei were enlarged and hyperchromatic, and some areas between the myocardial tissues were obviously fibrotic (Figures 1A,B).

We observed the myocardial tissue ultrastructure in the groups with electron microscopy. Compared with those of the control myocardial tissue, $\mathrm{Z}$ bands of myofibrils from the pediatric DCM cardiac tissue appeared enlarged, loose, and fuzzy, and the sarcomeres disappeared. Some myofibrils showed dissolution or breakage. Compared with the normal group, the DCM group did not show an abnormal number of mitochondria, but some mitochondria were swollen and dissolved, and the mitochondrial cristae were empty, blurred or even absent (Figure 2).

\section{The Gene Expression of Drug-Related Receptors on Cardiomyocytes in Children}

Using qRT-PCR, we analyzed the expression of PRR, REN, ACE, and NR3C2 of the RAAS in the LV tissues from control and pediatric DCM hearts. We found that the expression of PRR, REN, ACE was higher in children with DCM than adults $(p<$ 0.05) (Figure 3).

We measured the expression of ATP1A1, ADRA1, ADRB1, PDE3A, and NEP in the LV tissues from pediatric and normal hearts and found differences (Figure 4). ADRA1 and ADRB1 showed no significant differences between pediatric DCM samples and normal samples (Figures 4A,B). Both ATP1A1 and PDE3A levels were higher in pediatric DCM samples than in normal DCM samples $(p<0.05)$ (Figures 4C,D). NEP 

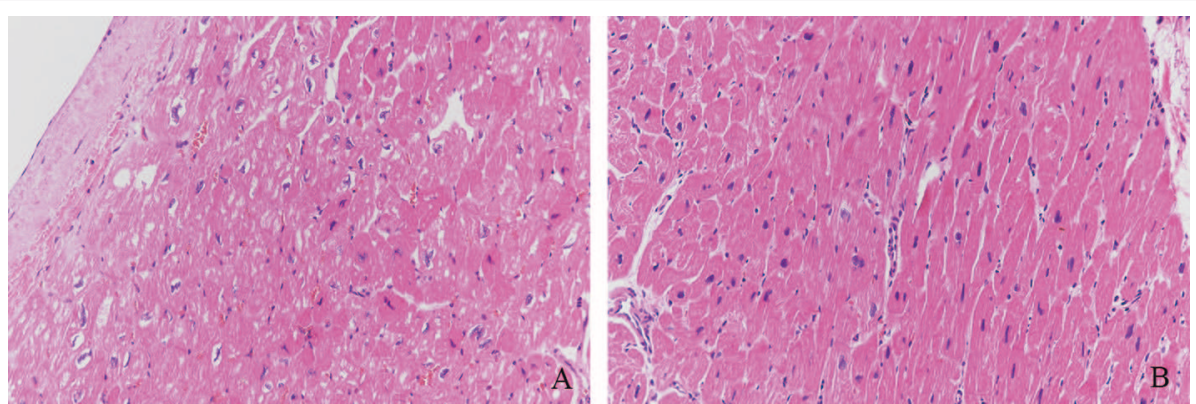

FIGURE 1 | Pathology of HE-stained myocardial tissue. (A) LV myocardial fibers of DCM samples showed variable thickness with blurred transverse striae. (B) Some myocardial fibers were thick, the nuclei were enlarged and hyperchromatic, and some areas between myocardial tissues were obviously fibrotic (Magnification $=200)$.
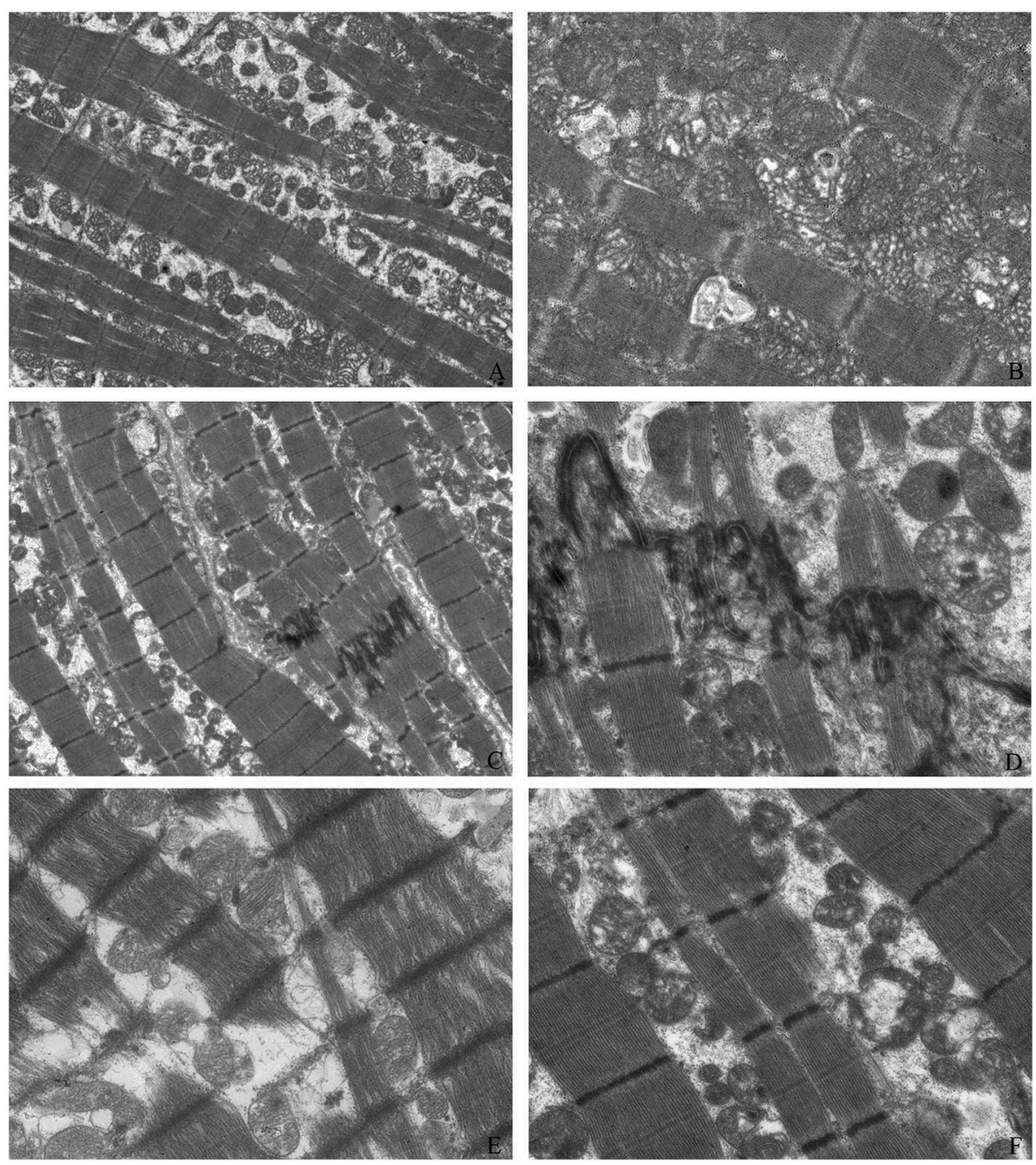

FIGURE 2 | Myocardial tissue ultrastructure. The ultrastructure of control myocardial tissue (A: magnification =2,000, B: magnification = 5,000 ); Z bands of myofibrils from pediatric DCM cardiac tissue appeared enlarged, loose, and fuzzy, and the sarcomeres disappeared (C: magnification $=2,000, \mathbf{D}$ : magnification $=5,000)$. Some myofibrils showed dissolution and breakage $(\mathbf{C}, \mathbf{E}$ : magnification $=5,000)$. Compared with those of the normal group, some mitochondria were swollen and dissolved, and the mitochondrial cristae were empty, blurred, or even absent (C,F: magnification $=5,000)$. 


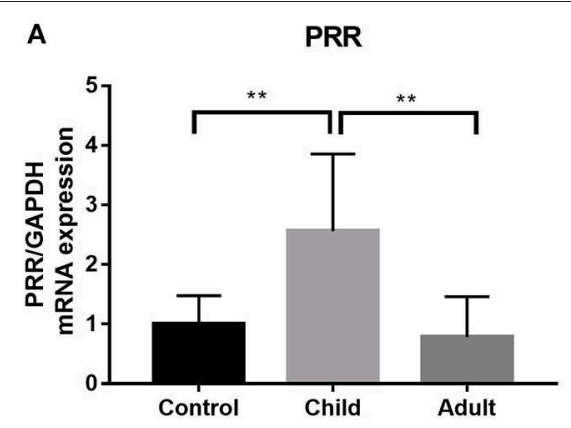

C

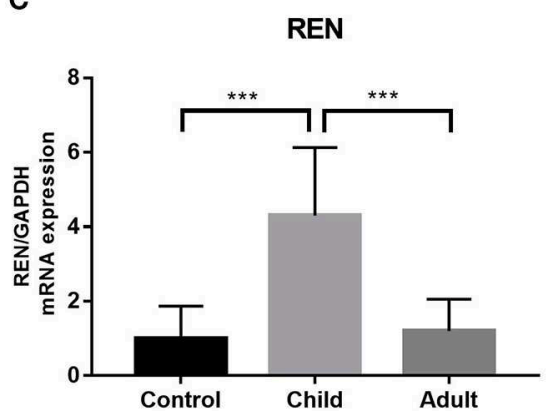

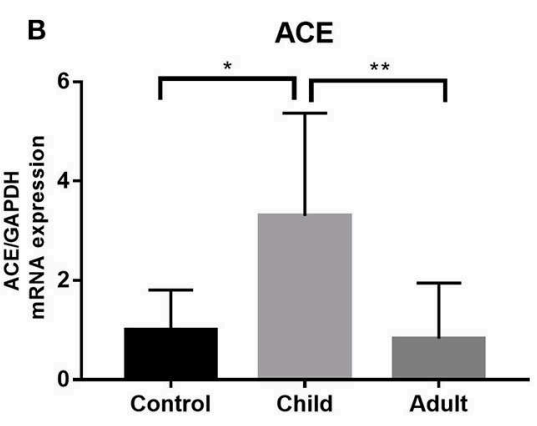

D NR3C2

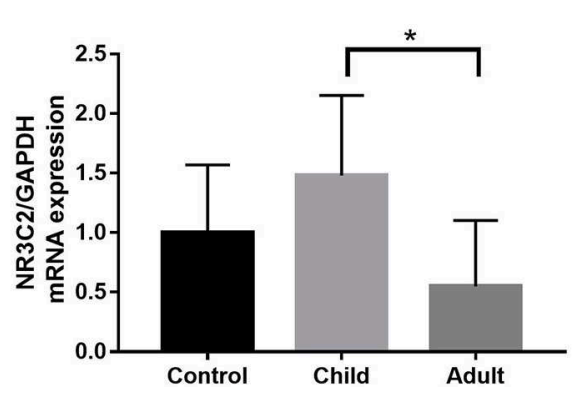

FIGURE 3 | Expression of PRR, ACE, REN, and NR3C2 in pediatric, adult DCM LV samples and control samples. (A) PRR expression was higher in pediatric DCM patients than controls. PRR expression was higher in pediatric DCM patients than adults. The significance was determined using comparison of two groups after ANOVA: $p=0.009, p=0.0023$. (B) ACE expression was higher in pediatric DCM patients than controls. ACE expression was higher in pediatric DCM patients than adults. The significance was determined using comparison of two groups after ANOVA: $p=0.017, p=0.008$. (C) REN expression was higher in pediatric DCM patients than controls. REN expression was higher in pediatric DCM patients than adults. The significance was determined using comparison of two groups after ANOVA: $p=0.0003, p=0.0006$. (D) NR3C2 expression was not higher in pediatric DCM patients than controls. Comparison of two groups after ANOVA determined that there was no difference in relative expression. NR3C2 expression was higher in pediatric DCM patients than adults. The significance was determined using comparison of two groups after ANOVA: $p=0.015$. ${ }^{\star} P<0.05,{ }^{\star \star} P<0.01,{ }^{\star \star \star} P<0.001$.

expression was significantly elevated in pediatric DCM compared to normal samples $(p=0.0008)$ (Figure 4E).

\section{Gene Expression of the Drug-Related Receptors on Cardiomyocytes in Adults and Children}

Using qRT-PCR, we analyzed the expression of PRR, REN, ACE, and NR3C2 of the RAAS in the LV tissues from adult and pediatric DCM hearts. These gene expression levels were higher in children with DCM than adults $(p<0.05)$ (Figure 3). We also measured the expression of ATP1A1, ADRA1, ADRB1, PDE3A, and NEP in child and adult hearts (Figure 3). ATP1A1, PDE3A, and NEP levels were increased in pediatric DCM and adult samples $(p<0.05)$ (Figures $4 \mathrm{C}-\mathrm{E}$ ). The expression of ADRA1 and ADRB1 was not significantly different between pediatric DCM and adult samples (Figures 4A,B).

\section{DISCUSSION}

The specimens selected in this study were all derived from the myocardial tissues of children with end-stage DCM. Even though the number of pediatric heart transplants has increasing in recent years, the number of pediatric heart transplants is still small relative to that of adult. So, it is not easy to get more samples of DCM heart. But this study firstly analyzed expression levels of drug relevant receptors and myocardial ultrastructure of DCM heart samples. Through electron microscopy, we observed that the end-stage myocardium in these children showed significant degeneration, the myofibrils focally dissolved and disappeared, and the mitochondria showed mitochondrial degeneration and vacuolation. Compared with that of adults, the myocardial ultrastructure in children with end-stage DCM was not significantly different (11).

The most common cause of pediatric HF is DCM, and the clinical prognosis of DCM is poor (12). The increase in the survival rate of these children is largely due to heart transplantation. While the preferred treatment for endstage $\mathrm{HF}$ is transplantation, children on waiting lists for heart transplantation have some of the highest mortality rates because of the limited number of heart donors (13). Therefore, identification of a suitable drug treatment to prolong the survival time before heart transplantation is urgently needed.

Although, the myocellular mechanisms of DCM in children are mostly unexplored, treatment strategies for HF in children are consistent with those in adults. Some clinical studies have found that the treatment of adult patients with HF reduced mortality. However, the same treatment did not improve prognosis in 


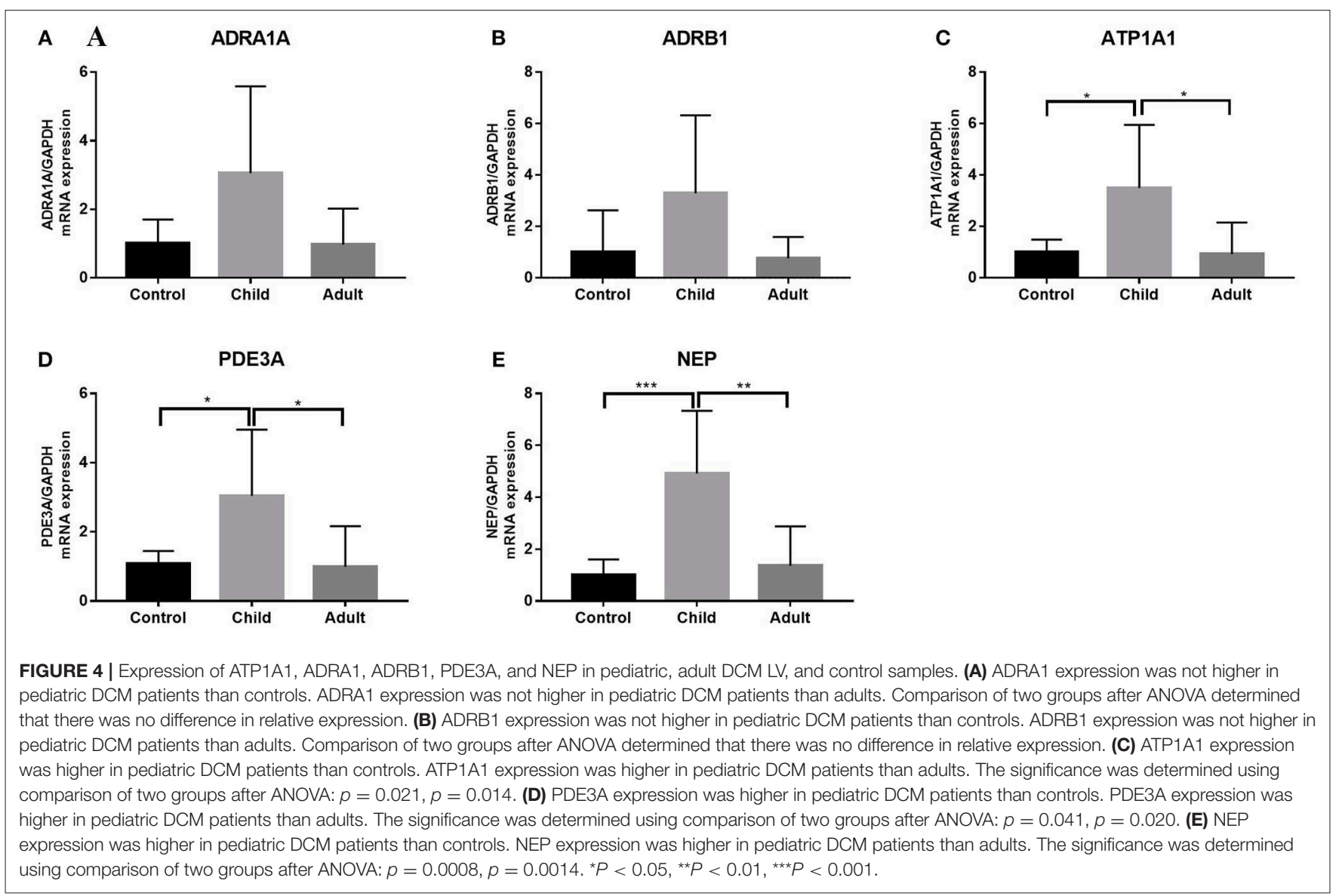

children (14). In general, pharmacotherapy for DCM in children is consistent with pharmacotherapy for DCM in adults. A transition from almost total use of digoxin and diuretics to widespread use of ACE inhibitors occurred in the 1980s (15), and another transition to second- and third-generation $\beta$-AR blockers occurred in the 1990s. Milrinone, a PDE3 inhibitor, improves myocardial performance without increasing afterload. Therefore, milrinone can be used to improve cardiac function in children with end-stage HF (16). In addition, LCZ696 was more effective in lowering blood pressure in patients with hypertension and reduced all-cause mortality in patients with HF compared to valsartan or enalapril $(17,18)$. With the development of research, many researchers have realized that the mechanism of DCM in children and adults may not be the same. We measured the gene expression of the corresponding receptors of drugs used to treat HF on cardiomyocytes, which provides a reference for the treatment of pediatric DCM.

RAAS activation can cause fluid retention, pulmonary venous congestion, pleural effusion, cardiac dilatation, and myocardial fibrosis, leading to clinical symptoms of HF in humans. Active renin exclusively controls the firstrate limiting step in the RAAS cascade, i.e., conversion of angiotensinogen to angiotensin I (19, 20). The PRR binds renin and prorenin and induces profibrotic intracellular signal cascades (21). The NR3C2 gene, which encodes the mineralocorticoid receptor, mediates the effects of aldosterone on salt and water balance within restricted target cells to reduce the load on the heart. In this study, we observed higher expression of PRR, REN, and ACE of the RAAS in the LV tissues from pediatric DCM hearts compared to those of normal and adult hearts. To date, the most commonly used therapy targeting the RAAS system to treat heart disease in children is ACE inhibitors. Our study indicated that ACE inhibitors may block cardiomyocyte expansion and could significantly mitigate HF. In addition, either PRR or REN receptor inhibitors may be effective in DCM. In the future, we will further study the effects of either PRR or REN receptor inhibitors on DCM.

Adult HF patients respond well to treatment with $\beta$-blockers because AR-mediated adaptation plays an important role in heart abnormalities in adult HF. However, a growing body of literature suggests that $\beta$-blockers are not as effective in treating pediatric HF as adult HF (22). Our results showed that ADRA1 and ADRB1 expression in pediatric DCM was not strikingly different from expression in normal samples. Therefore, we hypothesized that there are different adaptive $\beta$-AR and adrenalin signaling pathways in children with DCM compared to adults with DCM. This finding may indicate that $\beta$-receptor blockers are not effective in treating pediatric DCM.

Our results showed that ATP1A1 expression in pediatric DCM is higher than expression in normal conditions. The ATP1A1 gene encodes an alpha 1 subunit with good affinity for digoxin. 
Digoxin is a traditional medicine for the treatment of HF in children. Nakano et al. found that the level of myocardial cAMP in children treated with the PDE3 inhibitor milrinone increased, while the level of cAMP in adults treated with the PDE3 inhibitor remained low and unchanged (23). The results of our study confirmed the conclusions of previous studies and indicated that PDE3 inhibitor treatment is more effective in pediatric DCM than adult DCM.

In recent years, many studies have found that a combination of neprilysin/the RAAS inhibitor sacubitril/valsartan (LCZ696), which provides simultaneous neprilysin inhibition and angiotensin-II receptor blockade, was superior to ACEI/ARB therapy $(24,25)$. Our results showed that expression of the NEP gene, which encodes neprilysin, is higher than that in normal samples. This finding indicates that LCZ696 may be effective in treating children with DCM.

By comparing the expression of drug receptors related to heart disease in adult, child and normal myocardium, we confirmed that children and adults may not have the same response to DCM treatment in this study. ACE inhibitors, PRR or REN receptor inhibitors, PDE3 inhibitors and LCZ696 may be effective in children with DCM. However, $\beta$-receptor blockers are not valid treatments for pediatric DCM. Moreover, high receptor expression was observed in children. These data will improve drug selection for DCM patients, enhance DCM treatment and increase the survival rate.

\section{DATA AVAILABILITY STATEMENT}

All datasets analyzed for this study are included in the manuscript/Supplementary Files.

\section{REFERENCES}

1. Pinto YM, Elliott PM, Arbustini E, Adler Y, Anastasakis A, Bohm M, et al. Proposal for a revised definition of dilated cardiomyopathy, hypokinetic non-dilated cardiomyopathy, and its implications for clinical practice: a position statement of the ESC working group on myocardial and pericardial diseases. Eur Heart J. (2016) 37:1850-8. doi: 10.1093/eurheartj/ ehv727

2. Wilkinson JD, Landy DC, Colan SD, Towbin JA, Sleeper LA, Orav EJ, et al. The pediatric cardiomyopathy registry and heart failure: key results from the first 15 years. Heart Fail Clin. (2010) 6:401-13, vii. doi: 10.1016/j.hfc.2010.05.002

3. Kirk R, Dipchand AI, Rosenthal DN, Addonizio L, Burch M, Chrisant M, et al. The International Society for Heart and Lung Transplantation Guidelines for the management of pediatric heart failure: executive summary. J Heart Lung Transplant. (2014) 33:888-909. doi: 10.1016/j.healun.2014.06.002

4. Packer M, Carver JR, Rodeheffer RJ, Ivanhoe RJ, DiBianco R, Zeldis SM, et al. Effect of oral milrinone on mortality in severe chronic heart failure. The PROMISE study research group. N Engl J Med. (1991) 325:146875. doi: 10.1056/NEJM199111213252103

5. Price JF, Towbin JA, Dreyer WJ, Moffett BS, Kertesz NJ, Clunie SK, et al. Outpatient continuous parenteral inotropic therapy as bridge to transplantation in children with advanced heart failure. J Card Fail. (2006) 12:139-43. doi: 10.1016/j.cardfail.2005.11.001

6. Jiang X, Sucharov J, Stauffer BL, Miyamoto SD, Sucharov CC. Exosomes from pediatric dilated cardiomyopathy patients modulate a pathological response in cardiomyocytes. Am J Physiol Heart Circ Physiol. (2017) 312:H81826. doi: 10.1152/ajpheart.00673.2016

\section{ETHICS STATEMENT}

The studies involving human participants were reviewed and approved by Drug clinical trial ethics committee of Huazhong University of Science and Technology. Written informed consent to participate in this study was provided by the participants' legal guardian/next of kin.

\section{AUTHOR CONTRIBUTIONS}

JS and HP conception and design of the study. JL and YL performed the statistical analysis. PZ and ND collect sample. QG wrote the first draft of the manuscript. All authors contributed to manuscript revision, read and approved the submitted version.

\section{ACKNOWLEDGMENTS}

We are grateful for the support in sample collection and preparation provided by Yuan Yin, Wang Qiupeng, and Zhang Rong. The authors would also like to thank and acknowledge the Tongji Medical College, Huazhong University of Science and Technology of Heart Transplant Team for their contributions. This project was made possible by funding provided by the National Youth Natural Science Foundation of China (81500218).

\section{SUPPLEMENTARY MATERIAL}

The Supplementary Material for this article can be found online at: https://www.frontiersin.org/articles/10.3389/fped. 2019.00387/full\#supplementary-material

7. Hauck C, Potter T, Bartz M, Wittwer T, Wahlers T, Mehlhorn U, et al. Isoform specificity of cardiac glycosides binding to human $\mathrm{Na}+, \mathrm{K}+$-ATPase alpha1beta1, alpha2beta1 and alpha3beta1. Eur J Pharmacol. (2009) 622:714. doi: 10.1016/j.ejphar.2009.08.039

8. Dorn GW II. Adrenergic pathways and left ventricular remodeling. J Card Fail. (2002) 8:S370-3. doi: 10.1054/jcaf.2002.129267

9. Hambleton R, Krall J, Tikishvili E, Honeggar M, Ahmad F, Manganiello VC, et al. Isoforms of cyclic nucleotide phosphodiesterase PDE3 and their contribution to cAMP hydrolytic activity in subcellular fractions of human myocardium. J Biol Chem. (2005) 280:39168-74. doi: 10.1074/jbc.M506760200

10. Levin ER, Gardner DG, Samson WK. Natriuretic peptides. N Engl J Med. (1998) 339:321-8. doi: 10.1056/NEJM199807303390507

11. Paterick TE, Tajik AJ. Left ventricular noncompaction: a diagnostically challenging cardiomyopathy. Circ J. (2012) 76:155662. doi: 10.1253/circj.CJ-12-0666

12. Towbin JA, Lowe AM, Colan SD, Sleeper LA, Orav EJ, Clunie S, et al. Incidence, causes, and outcomes of dilated cardiomyopathy in children. JAMA. (2006) 296:1867-76. doi: 10.1001/jama.296.15.1867

13. Almond CSD, Thiagarajan RR, Piercey GE, Gauvreau K, Blume ED, Bastardi HJ, et al. Waiting list mortality among children listed for heart transplantation in the United States. Circulation. (2009) 119:71727. doi: 10.1161/CIRCULATIONAHA.108.815712

14. Kantor PF, Abraham JR, Dipchand AI, Benson LN, Redington AN. The impact of changing medical therapy on transplantation-free survival in pediatric dilated cardiomyopathy. J Am Coll Cardiol. (2010) 55:137784. doi: 10.1016/j.jacc.2009.11.059 
15. Dzau VJ, Colucci WS, Williams GH, Curfman G, Meggs L, Hollenberg NK. Sustained effectiveness of converting-enzyme inhibition in patients with severe congestive heart failure. N Engl J Med. (1980) 302:13739. doi: 10.1056/NEJM198006193022501

16. Alousi AA, Canter JM, Montenaro MJ, Fort DJ, Ferrari RA. Cardiotonic activity of milrinone, a new and potent cardiac bipyridine, on the normal and failing heart of experimental animals. J Cardiovasc Pharmacol. (1983) 5:792-803. doi: 10.1097/00005344-198309000-00014

17. McMurray JJ, Packer M, Desai AS, Gong J, Lefkowitz MP, Rizkala AR, et al. Angiotensin-neprilysin inhibition versus enalapril in heart failure. $N$ Engl J Med. (2014) 371:993-1004. doi: 10.1056/NEJMoa1409077

18. Solomon SD, Zile M, Pieske B, Voors A, Shah A, Kraigher-Krainer E, et al. The angiotensin receptor neprilysin inhibitor LCZ696 in heart failure with preserved ejection fraction: a phase 2 double-blind randomised controlled trial. Lancet. (2012) 380:1387-95. doi: 10.1016/S0140-6736(12)61227-6

19. Schroten NF, Gaillard CA, van Veldhuisen DJ, Szymanski MK, Hillege HL, de Boer RA. New roles for renin and prorenin in heart failure and cardiorenal crosstalk. Heart Fail Rev. (2012) 17:191-201. doi: 10.1007/s10741-011-9262-2

20. Weber KT. Aldosterone in congestive heart failure. N Engl J Med. (2001) 345:1689-97. doi: 10.1056/NEJMra000050

21. Peters J. The (pro)renin receptor and its interaction partners. Pflugers Arch. (2017) 469:1245-56. doi: 10.1007/s00424-017-2005-Z

22. Miyamoto SD, Stauffer BL, Nakano S, Sobus R, Nunley K, Nelson P, et al. Betaadrenergic adaptation in paediatric idiopathic dilated cardiomyopathy. Eur Heart J. (2014) 35:33-41. doi: 10.1093/eurheartj/ehs229
23. Nakano SJ, Miyamoto SD, Movsesian M, Nelson P, Stauffer BL, Sucharov CC. Age-related differences in phosphodiesterase activity and effects of chronic phosphodiesterase inhibition in idiopathic dilated cardiomyopathy. Circ Heart Fail. (2015) 8:57-63. doi: 10.1161/CIRCHEARTFAILURE.114. 001218

24. Li B, Zhao Y, Yin B, Helian M, Wang $X$, Chen F, et al. Safety of the neprilysin/renin-angiotensin system inhibitor LCZ696. Oncotarget. (2017) 8:83323-33. doi: 10.18632/oncotarget. 18312

25. Desai AS, Claggett BL, Packer M, Zile MR, Rouleau JL, Swedberg K, et al. Influence of sacubitril/valsartan (LCZ696) on 30-day readmission after heart failure hospitalization. J Am Coll Cardiol. (2016) 68:2418. doi: 10.1016/j.jacc.2016.04.047

Conflict of Interest: The authors declare that the research was conducted in the absence of any commercial or financial relationships that could be construed as a potential conflict of interest.

Copyright (C) 2019 Guo, Liu, Zhu, Liu, Dong, Shi and Peng. This is an open-access article distributed under the terms of the Creative Commons Attribution License (CC $B Y)$. The use, distribution or reproduction in other forums is permitted, provided the original author(s) and the copyright owner(s) are credited and that the original publication in this journal is cited, in accordance with accepted academic practice. No use, distribution or reproduction is permitted which does not comply with these terms. 